\title{
Ensuring sustainability of cultural heritage through effective public policies
}

Sustainability of cultural heritage is a complex issue and is rarely measured, especially at the project level, mainly due to a lack of universal heritage sustainability indicators. This is why many heritage projects are only partially sustainable. This article defines the concept of heritage sustainability and offers methods to measure and evaluate it. The research presented was conducted on good practice examples analysed in Greece, Italy, the Netherlands, Poland, Portugal, and Spain, which are assessed as strategic projects within specific EU, regional, or local policy instruments. The methodology, which explored possible indicators for evaluating the sustainability of cultural heritage investments, involved desk research and ex post analysis of selected heritage projects funded within a policy instrument, interviews with cultural heritage managers, focus groups, and comparative analysis of best practices analysed. The findings showed the crucial importance of cooperation and broad participation of various stakeholders, excellent cultural management, diversification of funding sources, community involvement and appropriation of cultural heritage by the community, respect for professional standards, innovative solutions, and careful spatial planning in ensuring heritage sustainability. Transferability of good practice examples is challenging because it depends on the local context. In order to be able to measure heritage sustainability at the project level, an all-encompassing set of cultural heritage sustainability indicators is proposed. To justify heritage investments, policy instruments may consider future priorities based on this set of indicators.

Keywords: cultural heritage, heritage sustainability indicators, heritage policies 


\section{Introduction}

The importance of heritage, both in terms of its intrinsic and instrumental values, is unquestionable and widely recognized. However, ensuring heritage sustainability is not an easy task and depends on a number of factors (e.g., financing, management, and human capacities). Heritage-related policies are the most important frameworks to ensure sustainability. If they fail to set appropriate measures, heritage sustainability may be threatened, even resulting in the demise of cultural properties. Failed investments due to inappropriate policy frameworks are also a concern.

Sustainable growth is the priority of the Europe 2020 Strategy (European Commission, 2010), which is also reflected in the EU Cohesion Policy (European Commission, 2014). This should have durable effects on regional development. Sustainability also applies to cultural heritage projects, which have been well funded from various EU sources. Calls within different heritage funding schemes usually require explanations or proofs to ensure the sustainability of potential projects. Although most projects do well on this task in theory, they sometimes fail in practice, leading to the shameful but common practice of "when the project is over, everything is over" (Steckiewicz, 2017: 34). The authors of this article do not know of any studies examining how many cultural heritage projects are sustainable after their funding period, but they have witnessed several projects that obtained funding without considering their sustainable future. This practice, although common knowledge, has rarely been openly discussed. It also reveals possible gaps in project evaluation, pointing to a need to reconsider evaluation mechanisms.

\subsection{Aims}

This article provides general recommendations for effective and efficient heritage-related public policies to ensure the sustainability of funded projects and to justify the resources invested. It is first necessary to reflect on the concept of heritage sustainability and to provide indications on how to measure heritage sustainability. After this, a general set of heritage sustainability indicators is proposed.

The concept of sustainable development has been widely discussed since the 1970s, but only in recent years has culture been introduced as an important pillar supporting sustainable development (Vecco \& Srakar, 2018). However, sustainability of cultural heritage per se, for its intrinsic values, is rarely considered. Although there are several reasons to ensure sustainability of cultural heritage (e.g., identity enhancement, community cohesion, and aesthetic, educational, and scientif- ic values), the obvious and usually most important reason is to justify public investments in cultural heritage. Improving public policies and consequently ensuring the durability and sustainability of cultural heritage is not an easy task because heritage is not treated by cultural policy only, but is often part of various public instruments (e.g., spatial planning, tourism, regional development, etc.), which calls for integrated governance of cultural heritage.

The next section presents the challenges encountered in conceptualizing cultural heritage sustainability and its further measurement. Then, the results of studying good practice examples of cultural heritage sustainability are presented, followed by a discussion. Finally, recommendations for improved public policies are presented.

\subsection{Conceptualizing heritage sustainability}

Sustainable development is defined as development that "meets the needs of the present without compromising the ability of future generations to meet their own needs" (World Commission on Environment and Development, 1987: 16). Culture in the context of sustainable development has come to the fore in the work of United Cities and Local Government (UCLG) and their Agenda 21 for Culture, adopted in 2009. This was an important step forward, which stressed the importance of culture, introduced as the fourth pillar of sustainable development (alongside the economic, social, and ecological pillars). The concept is usually referred to as cultural sustainability, but it differs greatly from sustainability of culture. The latter relates to the maintenance of culture per se - of practices, beliefs, and identity, including heritage, and the future existence of a given culture. Heritage sustainability follows the same line, and practice shows that public discourse usually focuses on its instrumental values and less on its intrinsic values. Discussed here is sustainability of cultural heritage in the sense of preservation "for future generations, while at the same time finding a balance and harmony between cultural heritage and the people who would like to experience it" (Jelinčić \& Glivetić, 2020). Intrinsic values are substantially underrepresented in different policy agendas in comparison with heritage instrumental values. In this way, the 2030 Agenda for Sustainable Development only marginally mentions the need for cultural heritage protection, but it fails to refer to its valorization or regeneration (Vecco \& Srakar, 2018). However, a number of EU-funded projects deal with the subject from a practical point of view with the aim of meeting the standards of heritage sustainability alongside effective EU investments.

The concept of heritage sustainability is extremely complex because there are many facets of sustainability against which the longevity of heritage projects can be evaluated. It is gen- 
Table 1: Usual challenges and responses to cultural heritage sustainability.

\begin{tabular}{|c|c|c|}
\hline General pressures & Specific challenges & Usual responses to challenges \\
\hline \multirow[t]{2}{*}{ Economic } & Lack of funding & $\begin{array}{l}\text { Direct funding (grants, inheritance, sponsorships and donations, } \\
\text { membership, co-branding activities, crowdfunding, retail, accommo- } \\
\text { dation and catering, events, private hire and rentals, interpretation, } \\
\text { user fees) }\end{array}$ \\
\hline & Lack of managerial capacities & $\begin{array}{l}\text { Capacity-building activities, training programmes development, } \\
\text { training of trainers, exchange of experience, transferability of knowl- } \\
\text { edge, development of heritage management plans }\end{array}$ \\
\hline \multirow{5}{*}{ Sociocultural } & Modernization & Appropriate use of the asset, use of technology, compromising \\
\hline & Standardization & Creative and innovative context-specific methods \\
\hline & Public perception & $\begin{array}{l}\text { Awareness raising and educational activities, visiteering (volunteer- } \\
\text { ing activities), living heritage activities }\end{array}$ \\
\hline & Political pressures & $\begin{array}{l}\text { Contested or dissonant heritage, awareness-raising campaign and } \\
\text { educational activities, engaging an external and unbiased expert }\end{array}$ \\
\hline & Social pressures (over-visitation, looting) & $\begin{array}{l}\text { Visitor management frameworks and tools, technology, international } \\
\text { legal frameworks against looting, drones to combat heritage loot- } \\
\text { ing, and scanning satellite photos of heritage }\end{array}$ \\
\hline \multirow{3}{*}{ Environmental } & Climate change & $\begin{array}{l}\text { Digital preservation of heritage, long-term strategic plans for reduc- } \\
\text { ing negative environmental impacts, education }\end{array}$ \\
\hline & Green economy & $\begin{array}{l}\text { Environmentally friendly material and equipment in renovation and } \\
\text { maintenance, circular economy principles (e.g. eco-friendly and } \\
\text { renewable energy systems) }\end{array}$ \\
\hline & $\begin{array}{l}\text { Natural risks (e.g. earthquakes, invasive } \\
\text { plants, floods) }\end{array}$ & $\begin{array}{l}\text { Regular monitoring; control, management, and combat of invasive } \\
\text { plants, and their eradication and replacement with non-invasive } \\
\text { species; digital preservation of heritage }\end{array}$ \\
\hline
\end{tabular}

Source: Jelinčić and Glivetić (2020); Boromisa, Tišma, and Ležaić (2016).

erally regarded in the social, cultural, economic, and environmental sense, which requires a holistic approach. The theoretical starting point for understanding heritage sustainability is research on the impact of "activities of various actors on cultural heritage according to political, economic and social interest" (Čeginskas, 2018). There are three key challenges in the discourse of cultural policy: limited ability to assess the impact of heritage on development, the problem of sustainability of heritage effects in the long run, and difficulties proving the existence of these effects. Therefore, research is seeking new methodological steps in assessing and managing cultural heritage (Azevedo, 2016).

Cultural heritage sustainability implies the evaluation of cultural, technical, economic, and environmental outcomes (ICOMOS, 2019), whereas the economic sustainability of cultural heritage is usually evaluated through the creation and maintenance of sustainable tourism development relevant for local communities (Pepe, 2018). Sustainability of social impacts often refers to the impact of heritage on local communities ( $\mathrm{La}$ badi, 2007; Carra, 2016), and the recent academic approach to cultural heritage management is to opt for community-defined values (Kajda et al., 2018). Environmental sustainabil- ity is manifested through the impact of climate disturbances on heritage (Gruber, 2008) on the one hand, and practice of the principles of the circular (Foster, 2020) and green economy (Hoff, 2011) on the other.

Evaluating the sustainability of cultural heritage still has a number of gaps related to determining projects' impacts and effects. For example, the definition of values is not clear (Garcia \& Cox, 2013), the emphasis is on economic measurements of sustainability, there are fewer indicators related to cultural, sociological, and environmental indicators, and negative effects are often reduced, whereas positive ones are emphasized. There are several quantitative evaluation methods using predominantly economic indicators, whereas sustainability is insufficiently measured by qualitative methods that answer the questions of how and why. Finally, in order to achieve sustainability of cultural heritage, it is important to create a consensus that can ensure successful implementation and maintenance of cultural heritage projects. Taking all this into account, it is extremely difficult to rate the importance of different aspects of sustainability and to decide which of them is more important. Providing appropriate and authentic conservation techniques to ensure that artistic, aesthetic, and historical heritage values 
are sustained may at the same time be extremely cost ineffective or may collide with environmental sustainability. The intention is therefore to approach heritage sustainability in a holistic and integrative way, ensuring that both effective and efficient measures are in place. This may pose various problems in ensuring that heritage sustainability is approached from diverse perspectives. "It proves that sustainability and durability of cultural heritage are not stand-alone concepts but often involve a negotiation process among its various aspects" (Jelinčić \& Glivetić, 2020).

When trying to ensure heritage sustainability in the economic sense, the greatest challenge for heritage durability and sustainability refers to the lack of funding. Modernization and standardization of heritage, political pressures (e.g., issue of contested or dissonant heritage), as well as the public perception of heritage values are considered sociocultural challenges. Concern with environmental pressures has rapidly increased in the latest decade and relates to climate change, the green economy, and natural risks (see Table 1).

In trying to achieve sustainability of cultural heritage values, the extensive literature (e.g., Torre, 2002; ICOMOS, 2013) usually refers to its uniqueness, its artistic, scientific, aesthetic, cultural, historical, educational, landscape, and community values. Challenges range from poor maintenance (possibly affecting aesthetic, educational, or scientific value), over-exploitation for tourism purposes (with impacts on potential damage, and even demise or gentrification), use of false or incorrect historical data or unauthentic heritage (affecting educational, scientific, cultural, or historical values), and disputes over the uniqueness of registered heritage assets to the loss of local community connection to cultural heritage (Jelinčić \& Glivetić, 2020).

One of the greatest challenges in achieving heritage sustainability today lies in poor management of heritage assets. This entails all management phases: planning, implementation, monitoring, and evaluation. Specific challenges in relation to heritage conservation and physical maintenance may also affect sustainability. However, these belong to specific professional knowledge and are not dealt with in this article.

\subsection{Measuring heritage sustainability}

One of the approaches to achieving heritage sustainability is to introduce concrete measures: a group of relevant activities with common impacts as a part of policy instruments. This, however, does not necessarily entail an effective and efficient outcome, as measured by the number of sustainable heritage projects. Due to a number of factors influencing heritage sustainability, different indicators to measure success in achiev- ing heritage sustainability are required. However, as much as there are a growing number of studies dealing with cultural indicators, knowledge about heritage sustainability indicators is scant (e.g., Noca, 2018). Research usually focuses on heritage tourism (UNWTO, 1996), and heritage sustainability is measured against indicators related to specific situations, such as in conflict and war regions (Vecco \& Srakar, 2018).

Cultural sustainability measurement is "organized around seven storylines: heritage, vitality, economic viability, diversity, locality, eco-cultural resilience, and eco-cultural civilization. These storylines are partly interlinked and overlapping, but they differ in terms of some contextualized aspects" (Soini \& Inger 2014: 213). As much as these storylines may equally be applied to heritage indicators, it is necessary to stress the importance of heritage in achieving cultural sustainability because it bears cultural capital to be passed to future generations. If measures to achieve heritage sustainability are carried out at the level of policy instruments, Colin Mercer's set of indicators for evaluation and assessment of cultural policies comes in handy. Four categories of indicators are proposed: 1) cultural vitality, diversity, and conviviality;2) cultural access, participation, and consumption; 3 ) culture, lifestyle, and identity; and 4) culture, ethics, governance, and conduct (Mercer, 2002). The first category relates to the dynamics of cultural economy, the second measures active cultural engagement, the third evaluates how culture affects specific lifestyles and identities, and the fourth relates to the role of culture in personal and community development. The indicators are proposed with the aim of contributing to human development; that is, to improving the quality of life, which can be in indirect relation to sustainability and can also be considered a heritage sustainability indicator. All of the proposed indicator categories could be adapted to cultural heritage, and partial attempts to do so were made by Axelsson et al. in 2013 for 290 Swedish municipalities. Along with the findings in this research, Mercer's set of indicators served as a basis for recommendations to improve policy.

Measuring heritage sustainability is further complicated by the fact that there are different levels of impact measurement; it can be at the policy level, but individual projects and programmes can also be assessed, as well as institutions. The usual cases assess proposed actions (projects, programmes, plans, or policies; Pope et al., 2017) and serve to identify possible gaps or failures in meeting the previously set objectives. In reality, despite the existing available sustainability measurement indicator sets, it is difficult to find a universal model (Agol et al., 2014). Even the UN Sustainable Development Goals to be achieved by 2030 hardly recognize the importance of heritage and fail to provide respective indicators. This is also the case with the EU Sustainable Development Strategy. Some 
researchers (Vecco \& Srakar, 2018) have attempted to correct it by adding themes related to cultural heritage site sustainability to headline indicators for each of the sustainable development themes. They proposed the following headline indicators: 1) conservation of cultural heritage, 2) cultural cohesion and integration of the local community, 3) protection of the natural and cultural ecosystem, 4) quality of cultural heritage site management, 5) the economic dimension of cultural heritage tourism for the host community and destination, 6) the social carrying capacity of the destination, 7) sustaining tourist satisfaction, 8) development and planning control over the cultural heritage site, 9) tourist activity seasonality, 10) tourism employment, and 11) transport related to tourism.

As much as the proposed indicators are valid, they are not comprehensive. The existing indicator sets generally seem to be suitable for higher vertical level measurement (e.g., international or national), whereas site-specific heritage attractions have rarely been measured and comprehensive indicator sets are not available for this purpose (Ren \& Han, 2018).

\section{Research method}

Research on good practice examples in heritage sustainability was carried out to assess heritage sustainability at the local level. Based on this, recommendations were proposed for improving the policy instruments that provide support to cultural heritage projects. The research was conducted within an EU-funded project (Internet 1) based on the premise that public policies can serve as catalysts for high-quality projects with a long-lasting impact on regional development. Six countries were studied: Greece, Italy, the Netherlands, Poland, Portugal, and Spain. They apply different approaches to cultural heritage funding with respect to related policy instruments (local, regional, or EU funds), and to ensuring heritage sustainability (e.g., economic, environmental, or social). Selected projects funded through different policy instruments were analysed. Additional good practice examples were analysed in order to identify factors influencing heritage sustainability. The research phases are presented in Figure 1.

The methodology consisted of various research methods: desk research and ex post analysis of the selected heritage projects funded within the respective policy instrument, interviews with cultural heritage managers responsible for selected cultural heritage projects, focus groups organized as a consultative body, and comparative analysis of the best practices studied.

Phase 1 analysed thirteen selected heritage projects implemented under respective policy instruments (Internet 1), which provided state-of-play information about the projects. This

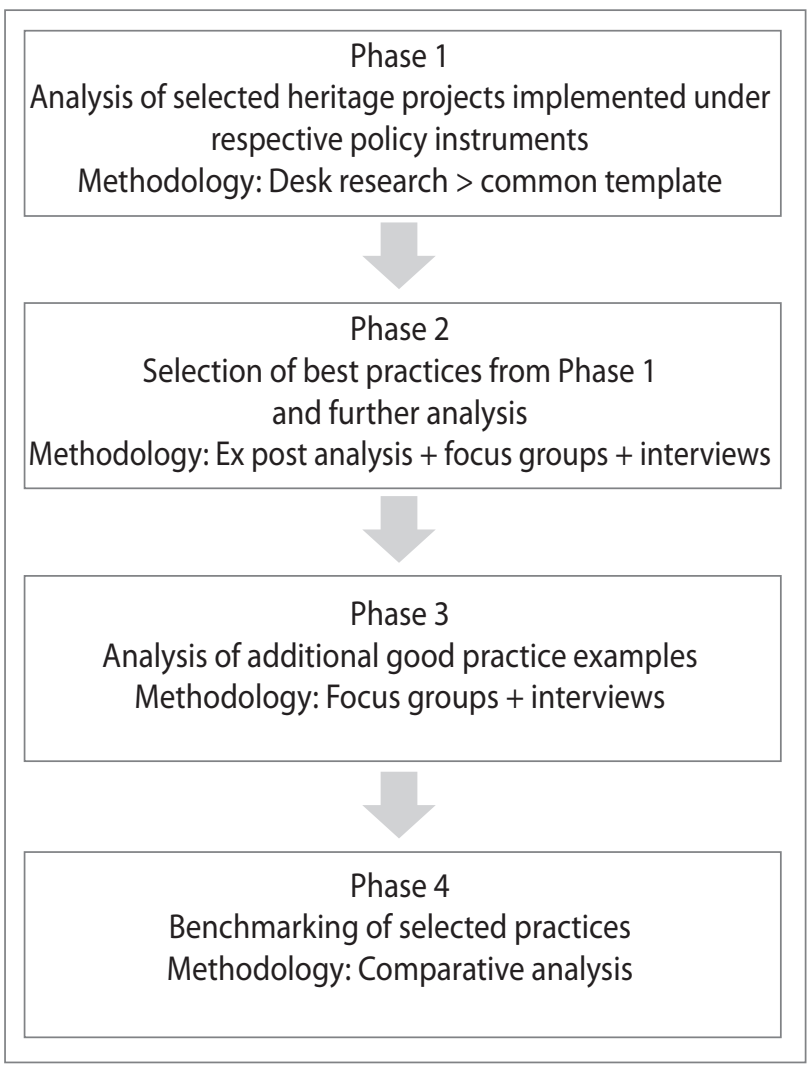

Figure 1: Research phases and methodology applied (illustration: authors).

phase had a descriptive character. A common template was designed, including a project description, its context, design, governance, financial sustainability, and conclusive remarks. Phase 2 selected seven best practices using ex post analysis and focus groups. The members of the focus groups discussed the projects and selected the best ones based on the total score the projects achieved in the evaluation exercise. Ex post analysis examined whether the goals of the project had been achieved and whether the results achieved justified the money spent. Good practice examples were analysed in terms of their effectiveness, relevance, impact, and sustainability (e.g., the actual situation with respect to planned activities, the contribution to society, sustainability, and auditing the financial statements). Focus groups were organized to select the best past cultural projects, assessing their sustainability, heritage values, and transferability. Phase 3 identified ten additional good practice examples based on interviews with cultural heritage managers. These examples were further analysed to identify factors influencing heritage sustainability. Thus, the total number of interviews was seventeen. For this purpose, a good practice template was designed with the same criteria used with the focus groups in Phase 2. The existing Interreg Europe good practice template served as a basis but was modified for this study. The criteria relied on standard models of heritage value estimates as defined by discipline-specific professional practice but were 
complemented with new ones, in line with contemporary heritage conservation and management. They were collected from various sources such as heritage management plans, international organizations' heritage-related documents, or cultural heritage evaluation reports (e.g., Rampton \& Carlberg, 2015) and divided into three groups: sustainability covering the usual four pillars (safeguarding cultural heritage, economic viability, environmental impact, and social impact), heritage values (scientific, aesthetic, cultural, historical, landscape, uniqueness, educational, local community, and economic value), and transferability (organizational model, policy-making, specific tools such as training, financing, management, and risk management). In addition, a set of questions was listed for the interviews with cultural heritage managers, which served as support in filling out the good practice template. This made it possible to identify key issues in achieving heritage sustainability. Phase 4 benchmarked selected best practices and identified key challenges. These were further analysed to create heritage sustainability indicators.

Focus groups meetings were organized at two levels: 1) in each country studied, and 2) at the research partnership level. The aim of focus groups in each country was to obtain expert opinions to support the selection of best practices to be analysed, along with expert comments on research instruments (e.g., templates for data collection) and final outputs (the results of individual research phases). The number of participants in the focus groups and their composition varied by country, based on the local context, but the groups mainly included cultural heritage managers, representatives of managing authorities, municipalities, tourism boards, local action groups, universities or research centres, cultural institutions, and consultants. The second type of focus group consisted of representatives of each country accompanied by researchers acting as knowledge managers and guiding the overall process. The aim was to discuss the research process in each country and adjust the course of the research accordingly.

The research was conducted between June 2018 and February 2020. The greatest challenge of the research was in the diversity of the good practice examples analysed, which require a specific management approach. This caused some difficulty in studying sustainability practices because they are measured by a variety of criteria. Thus, it was difficult to assess whether a certain example could be considered a sustainable practice because it was practically impossible to find one that satisfied all the criteria. The challenge was mitigated by employing a focus group approach with experts to decide what could be categorized as a good practice. However, the diversity of the good practice examples analysed was necessary to encompass a wide spectrum of indicators related to heritage sustainability, leading to the final heritage sustainability indicator set. Among all the assessment criteria, transferability was the biggest challenge because it greatly relies on the local context, which was outside the scope of this research. Minor limitations related to different levels of expert knowledge in policy planning, strategic development, and cultural heritage management were overcome by employing the focus group method at the partnership level.

\section{Results}

The results of the analysis of the thirteen selected heritage projects implemented under different policy instruments showed a positive correlation with different aspects of sustainability. All these projects can be considered sustainable, either economically, environmentally, or socially, and they affect the safeguarding of cultural heritage. Assessment of good practices implemented under respective policy instruments showed sustainability in some but not all aspects assessed (Table 2).

However, further analysis of some projects from Phase 1 alongside additional practices in seventeen interviews showed that not one of the practices complies with all of the criteria. Thus, some projects sustain heritage values but fail to comply with management-related criteria, or they show excellence in heritage interpretation but are not economically viable. Even so, the examples satisfy most of the criteria. However, not all of the criteria are equally important in ensuring the sustainability and durability of cultural heritage, which is greatly dependent on the context as well as the development objectives.

The interview analysis showed the crucial importance of cooperation and broad participation (in terms of vertical as well as horizontal policy, including various sectors and disciplines) in the cultural heritage project. In addition, excellent cultural management may greatly affect the sustainability of cultural heritage practice as may diversification of funding sources. The importance of highly emotional connections of the local community with their heritage ensures a strong premise for projects' success as well as local community participation in the project. Furthermore, respect for professional standards in the reconstruction of heritage buildings proves to ensure quality, and eventually also sustainability. Innovative solutions, if properly applied, play an important role in ensuring heritage sustainability. Careful spatial planning and community involvement (reintegration of heritage in both urban fabric and society) ensures valuation of heritage because it is part of citizens' daily lives. All the examples analysed may be considered transferable, but caveats are related to repurposing religious heritage because it is viewed differently in different countries. This may also prevent transferability of the practices. 
Table 2: Assessment of sustainability of good practices implemented under respective policy instruments.

\begin{tabular}{|c|c|c|}
\hline Country & Implemented practice & Areas in which sustainability is achieved \\
\hline Greece & MELINA: Education and Culture project & $\begin{array}{l}\text { Educational value, cultural value, specific tools: training, economic via- } \\
\text { bility }\end{array}$ \\
\hline \multirow{2}{*}{ Italy } & Stupinigi hunting roads* & $\begin{array}{l}\text { Social value, historical value, cultural value, environmental value, unique- } \\
\text { ness, educational value, landscape value, community value }\end{array}$ \\
\hline & Venaria Reale restoration & $\begin{array}{l}\text { Cultural value, historical value, landscape value, uniqueness, educational } \\
\text { value, community value, economic sustainability, governance model }\end{array}$ \\
\hline \multirow{2}{*}{ Netherlands } & $\begin{array}{l}\text { City wall area: parking solution through herita- } \\
\text { ge restoration }\end{array}$ & $\begin{array}{l}\text { Economic viability, environmental value, urban planning, response to } \\
\text { citizens' needs, educational value, historical value, scientific value }\end{array}$ \\
\hline & $\begin{array}{l}\text { Saint-John bulwark: hospitality and tourism } \\
\text { through (visible) heritage }\end{array}$ & $\begin{array}{l}\text { Environmental value, economic viability and sustainability, urban plan- } \\
\text { ning, community value }\end{array}$ \\
\hline \multirow{2}{*}{ Poland } & $\begin{array}{l}\text { Expansion of the Kielce Village Museum: Eth- } \\
\text { nographic Park in Tokarnia }\end{array}$ & Community value, educational value, economic viability \\
\hline & The Royal Castle in Chęciny & $\begin{array}{l}\text { Cultural value, environment, community value, historic value, spatial } \\
\text { planning, risk management, partial economic sustainability }\end{array}$ \\
\hline \multirow{3}{*}{ Portugal } & $\begin{array}{l}\text { Excavated Rock Wine Mills in the municipality } \\
\text { of Valpaços }\end{array}$ & $\begin{array}{l}\text { Historical value, educational value, cultural value, scientific value, econo- } \\
\text { mic viability }\end{array}$ \\
\hline & $\begin{array}{l}\text { Flax and Linen Museum in the municipality of } \\
\text { Ribeira de Pena }\end{array}$ & $\begin{array}{l}\text { Historical value, scientific value, cultural value, community value, econo- } \\
\text { mic viability }\end{array}$ \\
\hline & $\begin{array}{l}\text { Tresminas Interpretative Centre in the munici- } \\
\text { pality of Vila Pouca de Aguiar }\end{array}$ & $\begin{array}{l}\text { Cultural value, historical value, educational value, governance model, } \\
\text { economic viability }\end{array}$ \\
\hline \multirow{3}{*}{ Spain } & Natura Xurês-Gerês* & Spatial planning, economic viability, environmental value \\
\hline & $\begin{array}{l}\text { Cultural heritage of the Galicia-Northern Por- } \\
\text { tugal Euroregion: Valuation and Innovation }\end{array}$ & Governance model, organizational model \\
\hline & Dynamic Gerês-Xurês project* & $\begin{array}{l}\text { Community value, cultural value, environmental value, social value, } \\
\text { economic viability }\end{array}$ \\
\hline
\end{tabular}

Note: *Natural heritage projects involving cultural heritage.

\section{Discussion}

This research has confirmed the complexity of ensuring sustainability due to the vast array of sustainability aspects and their sociocultural, environmental, and economic sub-levels. Regarding the crucial issues that make up the concept of heritage sustainability, the research identified excellent cultural management, diversification of funding sources, emotional connections, community involvement, and broad participation of stakeholders. In addition, application of professional standards was identified as key in line with the preservation of artistic, aesthetic, and historic heritage values. New factors affecting heritage sustainability identified in the research relate to innovative solutions and careful spatial planning, and trans- ferability proved to be important at the policy-making level to justify investments. The local cases analysed did not comply with all the previously identified factors that heritage sustainability entails, which confirms the complexity of the concept of sustainability as well as its site-specific nature. The reason for the scarce indicator sets at the local level, as identified by Ren and Han (2018), might be sought in this fact. However, this does not mean that there is no need to measure heritage sustainability at a site-specific level or that sustainability indicators are not needed.

Regarding the measurement and evaluation of heritage sustainability, the findings showed that a number of aspects must be considered. Even if one indicator shows a practice to be sustainable, another indicator may not. Measuring heritage sus- 
tainability therefore requires a broad indicator set as a basis to ensure durable and sustainable heritage projects. Equally, it also helps improve the heritage-related policy instrument. Based on theory and this research, a set of general indicators for regular monitoring and evaluation of heritage projects is proposed. This could help cultural heritage managers and decision makers measure project sustainability and the efficiency of policy instruments. The design of the indicators, however, is rather complex and challenging because the literature offers only partial aspects of heritage sustainability, and the case studies investigated do not always cover all aspects of heritage sustainability. Another challenge is overlapping areas (e.g., local community engagement can be considered not only a sociocultural aspect related to heritage value for the community, but also an economic aspect). However, solutions have been found and the indicators are presented in three recommended sets: 1) sociocultural, 2) environmental, and 3) economic.

Sociocultural sustainability covers twelve areas, focusing on modernization challenges, standardization, public perception, heritage aesthetic or artistic values, historical values, cultural values, educational values, landscape values, scientific values, local community values, heritage uniqueness, and political and social pressures. Public policies may introduce measures in relation to each of the sustainability areas identified. In ensuring heritage cultural values, for example, possible measures may focus on stimulating heritage-related events or practices; heritage presence in artworks, stories, films, music, and so on; religious or spiritual importance; and the use of infrastructure for cultural creation. Indicator examples are the number of events or activities; the number of participants in events or activities; new heritage-related cultural productions; the number of consumers of newly produced cultural heritage-related products; religious or spiritual services or activities performed in a heritage asset; and the number of artists, community members, or visitors using heritage infrastructure for cultural creation. Sociocultural heritage sustainability is closely related to heritage-intrinsic values, ensuring the continuation of local identity as well as heritage authenticity.

Environmental sustainability covers three areas related to the challenges of climate change, environmental risks, and the circular economy or green economy. Regarding environmental risks (e.g., earthquakes, volcanic eruptions, invasive plants, and floods), accompanying policy measures may involve regular monitoring of the site for environmental pressures; control, management, and combat of invasive plants, and their eradication and replacement with non-invasive species; and long-term strategic plans for reducing negative environmental impacts. Proposed indicator examples are monitoring activities; interventions as a result of monitoring recommendations; activities to eradicate invasive plants; reduced negative environmental impacts; disincentives for changes in mobility behaviour, such as restricted traffic zones and urban tolls; and promotion of public transport, mobility plans, traffic calming zones, walking, and cycling. Environmental sustainability ensures safeguarding of built heritage and contributes to changing the behaviour of the local community.

Finally, economic sustainability is divided into seven major categories: planning; heritage product development; financial sustainability; marketing; employee management; visitor management; and monitoring, evaluation, and impact assessment. Accompanying public policy measures may refer to innovative heritage-related product development; targeted education and training measures for cultural production; availability of funding and investment for product development; capacities for action in transforming ideas, content, and values into products; access to infrastructure; and capacities for active appropriation of cultural forms. The proposed indicator examples are newly developed heritage products; spin-off products, related services, and experiences; training and trained persons; funding sources; creative and innovative heritage products; professionals with creative capacities; and products accepted and further promoted by employees, the community, and visitors. The importance of economic sustainability is primarily seen in ensuring appropriate financial means for heritage asset operation, and there is also an emphasis on heritage instrumental values, providing a strong foundation for regional development.

\section{Conclusion}

Sustainability of investments in cultural heritage is one of the key challenges for local and regional public policy. The main source of financing the protection and conservation of cultural heritage comes from national budgets and the EU budget. However, ex post analyses are rare and there is a lack of knowledge on the life and sustainability of projects. These issues are of particular interest for work on the development of European public policies and development plans in the coming period. In order to monitor the success of policy implementation at the national, regional, and local levels, it is crucial to set clear indicators to measure changes in local communities as a result of the investment of public funds.

Previous research on this topic provides extensive analytical material related to socioeconomic and environmental impact analyses, but there are no tailor-made integrated sets of indicators for assessing the sustainability of cultural heritage projects. This research has confirmed the complexity of heritage sustainability measurement, resulting in a number of aspects and related indicators to be taken into account. Based on the examples analysed, this research confirmed that cultural 
heritage projects are partially sustainable and it is practically impossible to find an example that would satisfy all the sustainability criteria. However, the diversity of the cases analysed made it possible to identify a full array of indicators, which may be considered and applied in policy instrument development, cultural heritage project proposal through ex ante assessment, or project implementation. Naturally, they may primarily serve in regular cultural heritage project monitoring and evaluation.

The proposed set envisages three main areas of sustainability assessment (economic, sociocultural, and environmental), with a number of specific areas. An important step was taken toward linking specific areas with measures as a part of a policy instrument and then with a series of specific measurable indicators. It is important to emphasize that the priorities (specific areas) can be selected depending on the needs and requirements of the project being assessed. In doing so, it is possible that some areas can overlap and can be evaluated from different aspects (e.g., landscape can be viewed through the prism of environmental sustainability or heritage values). This raises the question of the selection of indicators and their correct interpretation, which will depend on those that carry out the evaluation and monitoring processes. Future research, therefore, may focus on this dual nature of individual specific areas and related indicators while finding ways to integrate them. Regardless of the challenges encountered during the research, its contribution is seen in a systematic and comprehensive set of concrete indicators that can facilitate the monitoring process. In addition, they can be measured against previously set policy instrument priorities and measures. In this way, justification of cultural heritage investment at the policy level could easily be measured using ex post analysis. At the same time, it can serve to improve the policy instrument itself as well as the evaluation mechanisms for solving future gaps in project evaluation. This not only adds to heritage sustainability but ensures appropriate territorial planning and development alongside a full array of community benefits.

Daniela Angelina Jelinčić, Institute for Development and International Relations, Zagreb, Croatia

E-mail: daniela@irmo.hr

Sanja Tišma, Institute for Development and International Relations, Zagreb, Croatia

E-mail: sanja.tisma@irmo.hr

\section{References}

Agol, D., Latawiec, A. E. \& Strassburg, B. B. N. (2014) Evaluating impacts of development and conservation projects using sustainability indicators: Opportunities and challenges. Environmental Impact Assessment, 48, pp. 1-9. DOI: 10.1016/j.eiar.2014.04.001

Axelsson, R., Angelstam, P., Degerman, E., Teitelbaum, S., Andersson, K., Elbakidze, M., et al. (2013) Social and cultural sustainability: Criteria, indicators, verifier variables for measurement and maps for visualization to support planning. $A M B I O, 42$, pp. 215-228.

DOI: $10.1007 / \mathrm{s} 13280-012-0376-0$

Azevedo, M. (2016) The evaluation of the social impacts of culture: Culture, arts and development. Doctoral dissertation. Paris, Université Panthéon-Sorbonne. Available at: http://tel.archives-ouvertes.fr/ tel-01804118v2/document (accessed 4 Oct. 2020).

Boromisa A., Tišma, S. \& Ležaić, A. R. (2016) Green jobs for sustainable development. London, Routledge.

Carra, N. (2016) Heritage/cultural and social cohesion in the Project of Metropolitan City. Procedia - Social and Behavioral Sciences, 223, pp. 583-589. DOI: 10.1016/j.sbspro.2016.05.353

Čeginskas, V. L. (2018) The added European value of cultural heritage. The European Heritage Label. Santander Art and Culture Law Review, 4(2), pp. 29-50.

European Commission (2010) Europe 2020. A European strategy for smart, sustainable and inclusive growth. Communication from the Commission. Brussels. Available at: https://ec.europa.eu/eu2020/pdf/ COMPLET\%20EN\%20BARROSO\%20\%20\%20007\%20-\%20Europe $\% 20$ 2020\%20-\%20EN\%20version.pdf (accessed 3 Feb. 2020).

European Commission (2014) An introduction to EU Cohesion policy 2014-2020. Brussels. Available at: https://ec.europa.eu/regional_policy/sources/docgener/informat/basic/basic_2014_en.pdf (accessed 3 Feb. 2020).

Foster, G. (2020) Circular economy strategies for adaptive use of cultural heritage buildings to reduce environmental impacts. Resources, Conservation \& Recycling, 152. Available at: http://doi.org/10.1016/ j.resconrec.2019.104507 (accessed 4 Oct. 2020).

Garcia, B. \& Cox, T. (2013) European capitals of culture: Success strategies and long-term effects. Luxembourg, Publication Office of the European Union. Available at: http://www.researchgate.net/ publication/270586905 (accessed 3 Oct. 2020).

Gruber, S. (2008) The impact of climate change on cultural heritage sites: Environmental law and adaptation. Carbon and Climate Law Review, 5(2), pp. 209-219. Available at: https://www.jstor.org/stable/24324033?seq=1 (accessed 3 Oct. 2020).

DOI: $10.21552 / C C L R / 2011 / 2 / 181$

Hoff, H. (2011) Understanding the NEXUS. Background paper for the Bonn 2011 Conference: The Water, Energy and Food Security Nexus. Stockholm, Stockholm Environmental Institute. Available at: https:// www.water-energy-food.org/uploads/media/understanding the nexus. pdf (accessed 3 Oct. 2020).

ICOMOS (2013) The Burra Charter: The Australia ICOMOS charter for places of cultural significance. Paris, ICOMOS. Available at: http://openarchive.icomos.org/2145/ (accessed 14 May 2020).

ICOMOS (2019) European quality principles for EU funded interventions with potential impact upon cultural heritage. Manual. Paris, ICOMOS. Available at: http://www.openarchive.icomos.org/2083/ (accessed 3 Oct. 2020). 
Internet 1: https://www.interregeurope.eu/keepon (accessed 3 Oct. 2020).

Jelinčić, D. A. \& Glivetić, D. (2020) Cultural heritage and sustainability: Practical guide. Available at: https://www.interregeurope.eu/fileadmin/user_upload/tx_tevprojects/library/file_1586942702.pdf (accessed 14 May 2020).

Kajda, K., Marx, A., Wright, H. \& Richards, J. (2018) Archaeology, heritage, and social value: Public perspectives on European archaeology. European Journal of Archaeology, 21(1), pp. 96-117.

DOI: $10.1017 /$ eaa.2017.19

Labadi, S. (2007) Representations of the nation and cultural diversity in discourses on world heritage. Journal of Social Archaeology, 7(2), pp. 147-170. DOI: 10.1177/1469605307077466

Mercer, C. (2002) Towards cultural citizenship: Tools for cultural policy and development. Södertälje, The Bank of Sweden Tercentenary Foundation \& Gidlunds Förlag.

Nocca, F. (2017) The role of cultural heritage in sustainable development: Multidimensional indicators as decision-making tool. Sustainability, 9, pp. 1-28. DOI: 10.3390/su9101882

Pepe, A. (2018) The participatory process of a community involved in its biggest event: The case study "Matera European Capital of Culture 2019". II capitale culturale: Studies on the Value of Cultural Heritage, 17, pp. 275-297.

Pope, J., Bond, A., Hugé, J. \& Morrison-Saunders, A. (2017) Reconceptualising sustainability assessment. Environmental Impact Assessment, 62, pp. 205-215.

Ren, W. \& Han, F. (2018) Indicators for assessing the sustainability of built heritage attractions: An Anglo-Chinese study. Sustainability, 10(7), p. 2504. DOI: $10.3390 /$ su 10072540

Soini, K. \& Birkland, I. (2014) Exploring the scientific discourse on cultural sustainability. Geoforum, 51, pp. 213-223.

DOI: 10.1016/j.geoforum.2013.12.001

Steckiewicz, M. (2017) Effective policies for durable and self-sustainable projects in the cultural heritage sector. INTERREG Europe application form. Typescript.

Torre, Marta de la (ed.) (2002) Assessing the values of cultural heritage. Research report. Los Angeles, The Getty Conservation Institute.

UNWTO (1996) What tourism managers need to know: A practical guide to the development and use of indicators of sustainable tourism. Madrid, UNWTO.

World Commission on Environment and Development (1987) Our common future. Available at: http://www.un-documents.net/our-common-future.pdf (accessed 1 Oct. 2020). 